\title{
SEM Applied to the Development of Bioactive Surface of Dental Implants
}

\author{
José Félix Vilá $^{*}$, Julio César García ${ }^{2}$ and Abraham Guestrin ${ }^{3}$ \\ ${ }^{1 .}$ Electron Microscopy Laboratory, Center for Scientific Research and Technological Transfer to \\ Production - CICYTTP (CONICET - Prov ER - UADER), Diamante, Entre Ríos, Argentina \\ 2. NTI SRL, Paraná, Argentina \\ 3. Guestrin Ingeniería, Paraná, Argentina \\ * jfvila@cicyttp.org.ar
}

The placement of a dental implant consists of replacing a tooth in a terminal state by an implantprothesis joint with full funtion, adecuate shape, good aesthetics and healthy. The implantation is done by making a cavity in the bone applying a sequence of drills that are related to the length and width of the implant. Currently, this cavity is made $80 \%$ of the time drilling through the gum without making any soft tissues dissection in order to cause the minimum possible aggression to those tissues. To obtain rapid healing in and osseointegration - the intimate union between the titanium modified surface of the implant and the bone cells -, it is important to stimulate from the early stages the growth of the definitive bone bridge and to avoid the formation of elastic connective tissue.

Moreover, osteoblast-like cells can discriminate not only between surfaces of different roughness, but also between surfaces with comparable roughnesses but different topographies [1]. Accordingly, to achieve not only biocompatible but also osteoinductive (bioactive) characteristics, the bone-implant contact surface must have both physical (adequate porosity) and chemical properties [1] [2] that favor the deposition of calcium and phosphorus ions from the blood plasma, such Hydroxyapatite (HA) $\mathrm{Ca} 10(\mathrm{PO} 4) 6(\mathrm{OH}) 2$. These are the precursors that perform the mineral base of the future living bone [3].

Until recently, a surface with pores of 3 to 5 microns was considered ideal [2] [4]. Nowadays, a nanoporous surface (20 to 200 nanometers) within these micropores is sought [5] [6] to facilitate the connection of cellular extensions and fibers initially involved in the repair process, thus achiving a greater bone-implant contact and a faster union.

To obtain this type of surface, first an SLA (sanblasted-acid etched) treatment process [2] [4] was developed [4]. Various types of grit-blasting particles and different acid etching processes [7] were tested until the desired result was reached. At each stage of the development, a Desktop SEM was used to verify the results achieved. Series of images were made between 500x and 20,000x with $5 \mathrm{KV}$ and 10 $\mathrm{KV}$ in identical areas of the samples to compare the advances. In Figure 1 can be seen the microporous and nanoporous surface of an implant at different scales.

Once the desired surface morphology was achieved, the treatment that gives bioactivity to it was developed. In vitro tests with SBF (Simulated Body Fluid), an inorganic solution that simulates blood plasma [3] [7] [8], were performed according to ISO 23317 [9]. In titanium implants soaked in SBF, HA precipitates spontaneously on bioactive surfaces [3] [9]. This was confirmed by images on the Desktop SEM and EDS microanalysis by spots and mapping. In Figure 2 we can observe the formation of HA on the implant surface after 7 days and 21 days soaked in SBF. The spectra obtained show the elemental composition of the deposit in formation achieving high levels of HA compared to other studies [8]. 


\section{References:}

[1] JY Martin et al., Journal of Biomedical Materials Research 29 (1995), p. 389-401

[2] BD Boyan et al., Journal of Biomedical Materials Research 9 (1998), p. 77-85

[3] T Kokubo and H Takadama, Biomaterials 27 (2006), p. 2907-2915.

[4] L Le Guehennec, A Soueidan, P Layrolle and Y. Amouriq, Dental Materials 23 (2007), p. 844-854

[5] RA Gittens, R Olivares-Navarrete, Z Schwartz and BD Boyan, ActaBiomater10(8) (2014) p. 3363 3371

[6] D Khang et al., Biomaterials 33 (2012), p. 5997-6007

[7] K Deepak et al., Journal of The Royal Interface Society 9 (2012), p. 2145-2155

[8] M Kolafová et al., The International Journal of Oral \& Maxillofacial Implants, volume 32, number 6, (2017) p. 1221-1230

[9] Technical Committee ISO/TC 150, ISO/FDIS 23317:2012(E)
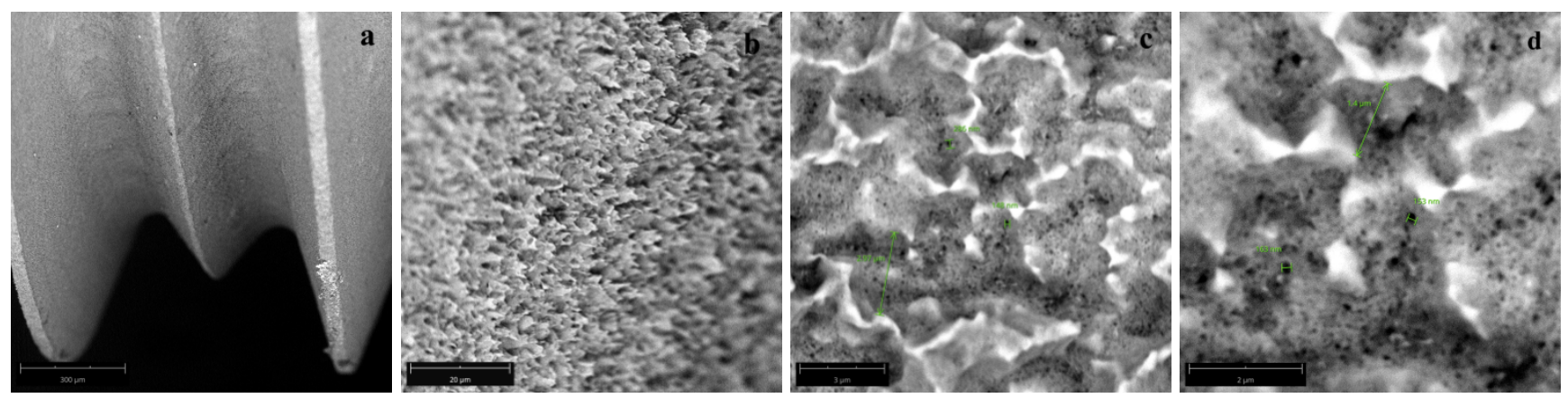

Figure 1: Surface of an implant at different scales: (a) the shape of the implant thread.(b) Morphology of micropores on the surface.(c) Size of the pores and the internal nanoporoussurface.(d) Closer image of nanopores. (SEM Phenom Pro, $10 \mathrm{KV}$, Special Holder)
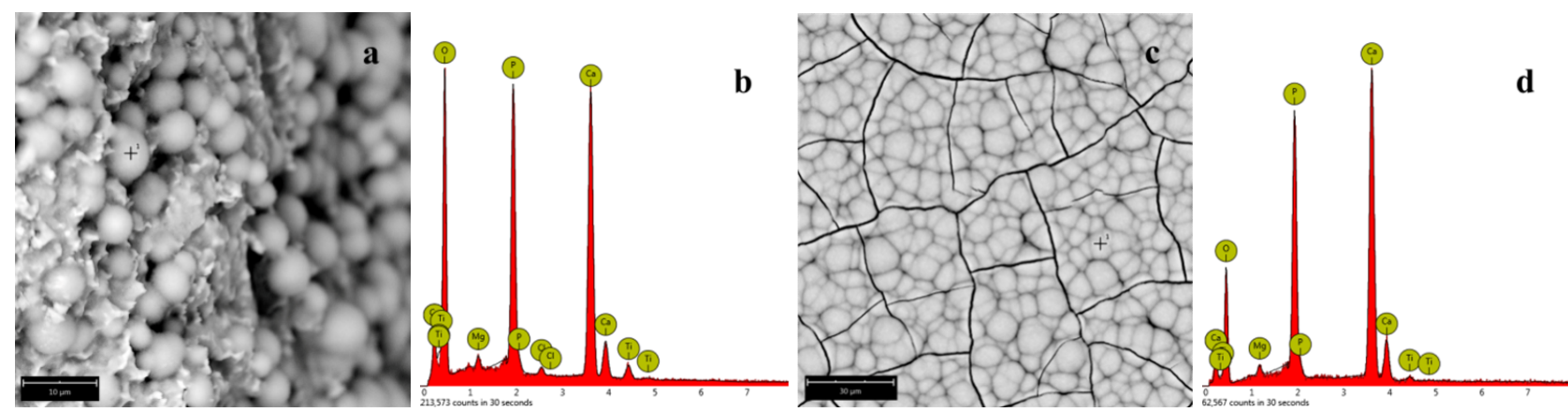

Figure 2: Hydroxyapatite precipitationon the implants surface soaked in SBF. In (a) the surface of a sample soaked in SBF 7 days and its EDS the spectrum (b) shows Ca 11.7\%, P 8.9\%, O 77.7\%, Ti 0.7\%, $\mathrm{Mg} 0.7 \%, \mathrm{Cl} 0.3 \%$. In (c) the surface of the sample soaked in SBF 21 days and the corresponding spectrum (d) shows Ca 20.4\%, P 13.1\%, O 65.4\%, Mg 0.8\%, Ti 0.4\%. (SEM Phenom ProX, 15 KV, Standard Holder) 